\title{
Problematising young male victims in twenty-first century English child sexual exploitation policy: A critical discourse analysis
}

\author{
iD Michael Fanner ${ }^{1}$ and ID David T. Evans ${ }^{2}$ \\ ${ }^{1}$ School of Health and Social Work, University of Hertfordshire \\ ${ }^{2}$ School of Health Sciences, University of Greenwich
}

Received 12 September 2021

Accepted for publication 3 November 2021

Published 18 December 2021

\begin{abstract}
Since 2000, English child sexual exploitation (CSE) policy has expanded, both in its understanding and response, to the increasing recognition and scale of the problem. Since 2011, with the move from statutory guidance to a government action plan, there was, for the first time, a substantial increase in CSE responses across English local authorities. Within English CSE policy, male victims are often referenced as a minority population in the 'dance' between gender-neutral and gender-specific guidance. For an observable eight-year period, specific CSE guidance was issued on 'Boys and Young Men' between 2009 and 2017. Using a qualitative case study methodology with 18 professionals in England, a critical discourse analysis, inspired by Foucauldian and Liminality theories, was undertaken to understand the 'ethics' within professional perceptions of male victims in contemporary CSE policy. The key findings highlight an incongruity of existing CSE vocabulary with male victims due to overtly gynocentric connotations. This article identifies how male victims have been perceived in the 'shadows' of their female peers, perhaps, as a policy 'afterthought', with consequential professional practice. Essentially, male victims have been implicated through this gendered conceptualisation and are assembled awkwardly on the surface of mainstream CSE discourse in England.
\end{abstract}

Keywords: gender, child sexual exploitation, critical discourse analysis, Foucault, youth policy, child protection

\section{Introduction}

In England, child sexual exploitation (CSE) is a decadeold conceptualisation defining a wide range of situations and circumstances, of typically non-familial, out-of-the-home, sexual exploitation of children. CSE was originally known as child prostitution (Phoenix, 2002; Melrose, 2013). In 2011 particularly and subsequent years, CSE sustained a concerted, widespread disapproval on the 'failing' infrastructures designed to protect children from abuse in the media, charity, political and high-profile inquiries, creating pressure to improve government systems beyond another cycle of statutory guidance (Barnardo's, 2011; Bingham et al., 2016; Coy, 2016). In response to the disapproval observed in 2011, the English government published the Tackling Child Sexual Exploitation Action Plan (Department for Education (DfE), 2011) that set out significant requirements for local authorities to develop multi-agency CSE responses. Jago et al. (2011) had identified that only one third of local authorities had implemented previous national CSE policy, but the DfE (2011) Action Plan had instigated an increase to two-thirds of local authorities developing or planning to develop a CSE response (Paskell, 2012), demonstrating for the first time a significant effort in CSE policy implementation.

Within the last decade, political and media representations of CSE has generated and propelled resultant social constructions, preoccupying a highly gendered and ethnic lens (Cockbain, 2013; Brayley, Cockbain and Gibson, 2014). 
These lenses have silenced other victim groups through a dominating focus on young able-bodied, white female victims and Asian working-class male offenders, as well as 'celebrity' sex offenders, majorly influencing contemporary policy innovations in 'tackling' CSE threats (Cockbain, 2013; Fanner, 2019). Furthermore, Melrose (2013), in her critical discourse analysis of CSE, identified that the current term is problematic on four accounts: 1) the word 'child' is often associated with innocence and does not cater for the full age range of children from infancy to $18 ; 2$ ) the term 'child' within CSE is often that of a female and her sexual agency (passive sexuality); 3) the term ignores marco factors surrounding CSE such as poverty, and; 4) the term exclusively focuses on CSE as adult morality issue rather than also recognising the potential sexual agency of young people.

Within England, favourable outcome in child welfare assessments is primarily determined through practitioners enacting professional judgement (Hicks, 2014; Jones, 2014). Whilst professional judgement allows practitioners great flexibility in determining the needs of children, Taylor and White (2001) observed a shift within social work in the 1980s to adopt a technical-rational approach in the articulation of professional judgement to standardise, regulate and monitor practice. Taylor and White argued that a technical-rational approach tends to over-simplify classifications of child abuse language, both in the vocabulary and emotional and subjective narrative, in the assessment of practical-moral situations such as abuse. To further contextualise professional judgement, there has been a parallel development in the reduction in child protection vocabulary available to professionals (Calder and Archer, 2016) alongside an increase in overt sexualisation of youth culture (Plummer, 2003; Attwood, 2010). These aforementioned observations produce a paradoxical, yet highly-charged, context that further generates complexity in the governmentality of CSE.

Identifying young male victims within these contemporary policy analyses/discourses therefore becomes increasingly complex and multi-faceted (Fanner, 2019). Although young male victims of CSE were once historically referred to as 'rent boys' (McNaughton Nicholls, Harvey and Paskell, 2014), their recent discursive social construction has been until now, under-theorised and under-examined. This article begins this much-needed theorisation/examination of young male victims, through the reporting of findings from a genealogically-focused ethical analysis (Arribas-Ayllon and Walkerdine, 2008; Dean, 2010; Garland, 2014), inspired by Foucauldian and liminality theories, of professionals' perceptions of young males in CSE policy, i.e. expert discourses, from the first author's PhD study.

\section{England's policy positions on young male victims since 2000}

English policy terminology describing and defining CSE has, overtime, epistemically transformed: At the start of the millennium, 'child prostitution' became known as 'children involved in prostitution' which, in turn, became 'sexually exploited children' and then 'child sexual exploitation' (Fanner, 2019). Although it should be noted a distinction between 'child prostitutes' and 'rent boys' existed in the initial recognition of the exploitation of children in the sex industry (e.g. Swann and Balding, 2002), with the UK's Children Act 1989 as the sole, formal protective mechanism to then child prostitutes (Phoenix, 2002). The Safeguarding Children Involved in Prostitution (SCIP) guidance (Department of Health/Home Office (DH/HO), 2000) was the first formal policy to separate children from adults within commercial sex markets. This policy departure distanced itself from the historical bifurcation of governing male and female sex workers (regardless of age) in separate legislation i.e. Street Offences Act 1959 and Sexual Offences Act 1967 (Melrose, 2013). Whilst no male-specific advice was issued in SCIP, the age of consent between heterosexuality and homosexuality was noted, 16 and 18, respectively. SCIP, however, presented one practice example of a charity working with young males, that claimed the single reason for their involvement in prostitution was due to social isolation caused by direct experience of homophobia. Their involvement presented with co-existing substance misuse problems and a history of intrafamilial abuse, depicting a policy reality that young males were particularly vulnerable to negative sexuality. In 2001, from a sample of 42 Area Child Protection Committees (now, Local Safeguarding Partnerships), Swann and Balding (2002) calculated on average that for every area there were 19 females and three males by CSE affected in England.

The nine-year, largely gender-neutral SCIP ended with the introduction of Safeguarding Children and Young People from Sexual Exploitation supplementary guidance (Department for Children, Schools and Families (DCSF), 2009) to the Working Together To Safeguard Children: A guide to inter-agency working to safeguard and promote the welfare of children (HM Government, 2006). The DCSF (2009) guidance offered specific advice on young males, stating up to a third of all victims were male, recognising that they differed in terms of surveillance ('more difficult to detect'), service engagement ('harder to work with') and disclosure ('less willing to disclose'). Coincidentally, this numerical statement can be supported by Cockbain, Ashby and Brayley (2015) analysis of Barnardo's CSE service user database comprising of 28 services in England, that males 
accounted for $33 \%$ of 9,042 children affected by sexual exploitation aged between eight and 17, during 2008 and 2013. Cockbain, Ashby and Brayley particularly identified that young males were not equally distributed throughout the country and proposed several geographical variations from suggestions made by service managers within Barnardo's: 1) the individual practitioners' own awareness and confidence in their ability to deal with young males and awareness raising with colleagues; 2) the nature and type of CSE training practitioners had received; 3 ) the nature of services provided and whether young males were included in funding agreements and service design.

The 2009 specific advice produced a list of possible indicators of young male involvement with two genderexclusive indicators that were particularly noteworthy in the depicted policy reality of their sexual exploitative experiences, and more distantly, sexuality. These indicators included 'aggressive or violent and sexually offending behaviors', and 'cottaging', i.e. sexual activities in public toilets, considered problematic with social integration. Whilst the DCSF (2009) guidance was an important milestone for young male victims, the content did not specify how to address gender-specific needs (Fanner, 2019). The DfE (2011) Action Plan maintained the definition and practice expectations of responding to CSE as according to the DCSF (2009) guidance yet was presented as an action plan to local authorities rather than statutory guidance.

The DCSF (2009) guidance remained for eight years until the return of gender-neutral CSE guidance in 2017, entitled Child sexual exploitation: definition and guide for practitioners (DfE, 2017), and again in 2021 with the publication of the Tackling Child Sexual Abuse Strategy (Home Office, 2021). Both contemporary policies make allbut-in-name, passing references to young male victims. Between 2013 and 2016, the DfE commissioned a, nowdefunct, male-CSE specialist voluntary sector project to work with CSE projects across England to nationally develop and share learning on best practices that focused on young males affected by CSE (Carey, 2021). No independent research or evaluation, however, exists on how effective this commissioned work was.

\section{Literature review}

Fanner (2019) undertook an interpretative, theory-driven synthesis review, namely critical realist synthesis (Wong et al., 2013), of the literature pertaining to English policy on CSE between the years 2000 and 2019 to identify the sociopolitico-historical relationships between national CSE policy, local policy implementation and young male victims. Fanner
(2019) analysed the literature through the four tenets of critical realism: searching for generative mechanisms (the underlying, beneath workings of how things work); adopting a multilayered perspective of reality; emphasising the relationships between structure, culture, and agency; and critiquing the prevailing social order (McEvoy and Richards, 2003) in the identification and refinement of programme theories. Programme theories are used to explain how policy interventions are meant to operate (usually through national policy intentions) and are then refined through a critical realist understanding of findings within the literature (Pawson, 2006). Rather than purely focusing on the outcomes of literature, critical realist synthesis differs by understanding the context and mechanisms that lead to outcomes (Wong et al., 2013). Fanner (2019) developed four programme theories that incrementally provided foundation for how young male victims were 'catered for' within CSE policy through a multilayered perspective of reality and the identification of causal mechanisms of outcomes (Figure 1; see appendix 1) and included:

- Programme Theory 1: From Child Prostitutes to Child Victims

- Programme Theory 2: Developing Local Responses to CSE

- Programme Theory 3: Working with CSE Victims

- Programme Theory 4: Focusing on Young Male Victims

This article focuses on the findings from the fourth programme theory, but the full critical realist synthesis can be found in Fanner (2019).

Only one national study exists on the implementation of DCSF (2009) guidance (Jago et al., 2011), but the study very minimally explored the nature of young male victims due to the low number of males reviewed in their study ( 92 males out of 1064 cases). Approximately only one half of a page of the 71-page report by Jago et al. (2011) explored young male victims, specifically, so depth of understanding was limited. Jago et al., (2011), however, stated that young males were harder to identify due to societal issues around sexual exploitation and sexual consent, which meant either they were not referred to services, or were missed by professionals due to misinterpreted signs of CSE. A small number of studies have examined practitioners' perceptions of young males, or gender exclusivity (Hudson and Rivers, 2002; McNaughton Nicholls, Harvey and Paskell, 2014; Walker, 2014; Donovan, 2014; Cockbain, Ashby and Brayley, 2015), with a smaller number reporting on young males in some way (Crawley, Roberts and Shepherd, 2004; Scott and Skidmore, 2006; Jago 
et al., 2011; Hallett, 2015). Four key themes emerged from this literature including: societal / policy issues, child welfare practitioner issues, perceptions of young male victims including those identifying gay, bisexual or trans* (abbreviated as 'GBT+', an inclusive abbreviation of young males who have sexual/romantic attraction to the same or more than one gender and/or do not self-identify with cisgendered labels), and the key services to be involved.

Structurally, existing discriminatory societal attitudes and stereotypes on gender, masculinity and homophobia greatly impact on the identification of young male victims (Jago et al., 2011; McNaughton Nicholls, Harvey and Paskell, 2014) and can lead to young males identifying as GBT accepting and normalising CSE experiences (Donovan, 2014; Walker, 2014). These societal attitudes transfer to an assumed gendered victimhood within policy and practice, for example female victim-only representation in CSE education to young people (McNaughton Nicholls, Harvey and Paskell, 2014). Whilst young males are perpetrated in near similar ways to young females (McNaughton Nicholls, Harvey and Paskell, 2014), three characteristics were perceived as specific to them, including: 1) being involved in CSE three years before females, aged 8 (Crawley, Roberts and Shepherd, 2004), 2) difficulties in responding emotionally to CSE (McNaughton Nicholls, Harvey and Paskell, 2014), and; 3) in discussing their sexuality with practitioners, which result in two scenarios: a) an increased a denial of CSE with an adult male (Scott and Skidmore, 2006) and/or b) feared being told they were in denial of their sexual orientation (McNaughton Nicholls, Harvey and Paskell, 2014). Practitioners also believed that many developmentally related CSE risks and vulnerabilities often associated with the chronological age of a young person are more aligned to those identifying as a cisgendered and/or heterosexual, as many GBT+ males 'come out' and become sexually active later in their adolescence in comparison (Donovan, 2014).

Perceptions of issues specific to child welfare practitioners included: misinterpretation of young males presenting to services (Jago et al., 2011; McNaughton Nicholls, Harvey and Paskell, 2014), knowledge gaps in responding to young male victims (Hudson and Rivers, 2002) and lack of direct experience/awareness of male CSE risks (Hudson and Rivers, 2002; Jago et al., 2011; Hallett, 2015). Practitioners who reported experience with lesbian, gay, bisexual and trans* (LGB\&T+) communities identified specific issues related to the LGB\&T+ sub-cultures including promoting nonheterosexual activities such as promiscuity (Scott and Skidmore, 2006) and a highly-sexualised objectification of youth with prized physical appearances (so called, body fascism) perceived to lead young males to accept unsuitable partners (Walker, 2014). Specific to CSE, practitioners perceived LGB\&T+ communities to label sexual activities differently to heterosexual (or mainstream) CSE (McNaughton Nicholls, Harvey and Paskell, 2014) and young males had a significant lack of safe social spaces to explore their sexuality and instead used over-sexualised, smartphone applications such as Grindr (McNaughton Nicholls, Harvey and Paskell, 2014; Donovan, 2014). In light of these specific CSE experiences of young males, especially those who identified as GBT, practitioners felt LGB\&T+ organisations were ideally placed to work with them as they are acutely aware of the actual reality of the sexuality development and CSE risks, able to provide assertive outreach services perceived to ascertain better engagement (Hudson and Rivers, 2002) as well as providing specific sexual identity/'coming out' support (McNaughton Nicholls,Harvey and Paskell, 2014; Donovan, 2014). None of the studies reported any theoretical positioning or analysed the relationship between practitioners' perceptions of young males and national genderneutral and gender-specific CSE policy.

\section{Methods}

The study explored how the experiences, understandings, and perceptions of young male victims of CSE, were presented within the expert discourses of policy, since the introduction of DfE (2011) Action Plan. A geographical case study was selected as a meaningful way of gathering in-depth crosssectional data to ascertain the professionals' perceptions on young male victims within a local authority area. As determined by Fanner's (2019) literature review, specific inclusion criteria were determined in order to gain a richness of multiple perspectives within specific contexts (Lewis and McNaughton, 2014). The specific criteria included: 1) a high English Indices of Multiple Deprivation score; 2) a sociohistorically relevant and visible LGB\&T+ scene; and 3) a developed CSE policy response to the DfE (2011) Action Plan. The selected case study was a metropolitan English local authority with a regional CSE program, consisting of geographically-spread, co-located multi-agency teams using standardised protocols, guidance, referral processes, assessments and interventions.

A total of 18 participants took part in semi-structured interviews through purposive and snowballing sampling and were either professionals with responsibility for the screening, referral, assessment and/or intervening with young people atrisk of CSE or were policy influencers or makers with relevance to CSE (see Table 1). Participants had an array of experiences of working with young males, ranging from one or two clients to several hundred, with 14 reporting more than five years' pertinent experience. The interviews were 
conducted, over eight months, between January 2015 and August 2015 and took place either at participant's workplaces or over the telephone. The interview schedules included topics such as perceptions of young males in national and local policy and practice and encouraged participants to reflect on their previous work with young males to illustrate their perceptions. Voluntary participant consent was required prior to interviews and confidentiality was always assured, with the exception of when someone was at risk of, or subject to harm. The University of Greenwich Ethics Committee approved the study (UREC/13.2.5.12) prior to data collection and no ethical issues arose.

Table 1. Number of participants interviewed within differing institutions

\begin{tabular}{|c|c|c|}
\hline $\begin{array}{c}\text { Type of } \\
\text { Institutions / } \\
\text { Agencies } \\
\text { Approached }\end{array}$ & $\begin{array}{c}\text { Number of } \\
\text { Participating } \\
\text { Institutions / } \\
\text { Agencies }\end{array}$ & $\begin{array}{c}\text { Number of } \\
\text { Participants } \\
\text { Interviewed }\end{array}$ \\
\hline $\begin{array}{c}\text { National Policy } \\
\text { Influencing } \\
\text { Institution }\end{array}$ & 2 & 2 \\
\hline $\begin{array}{c}\text { National Policy } \\
\text { Making } \\
\text { Institution }\end{array}$ & 1 & 1 \\
\hline $\begin{array}{c}\text { Institutions / } \\
\text { Agencies within } \\
\text { the defined Case } \\
\text { Study }\end{array}$ & 4 & 15 \\
\hline Total & 7 & 18 \\
\hline
\end{tabular}

The interview data were interpreted through a critical discourse analysis following the methodological guidance of Arribas-Ayllon and Walkerdine (2008) to illuminate young male-sensitive knowledge. The authors advise there are no 'hard or fast' rules with undertaking such analysis, but after deciding upon theoretical criteria, a selection of statements from the transcripts can take place. To assist with the interpretation, framework analysis (Ritchie and Spencer, 2003) was used to organise the process of data management, by placing and prioritising key statements (from participants' perceptions) into Microsoft Excel sheets. Firstly, each interview transcript was indexed and coded to identify initial discourses (or emerging themes), in line with Foucauldian and Liminality (Turner, 1969) theories, and secondly, all coded statements were then themed into individual framework matrices as discourses developed. The complete individual framework matrices then allowed further analysis to identify specific trending or minority discourses on young male victims for writing up.

\section{Alternative critical theories and child sexual exploitation}

Brayley, Cockbain and Gibson (2014) have observed the implications of gender within CSE research is underdeveloped, so a genealogical approach was adopted to investigate previous and current epistemology (Fanner, 2019). Within the development of the study focus, the authors considered the historical and contemporary theoretical debates that had influenced the social governance of sex, sexual violence, and the positioning of children, drawing reference to the surge in social constructionism surrounding sexual violence. Green (2005) recognised that, historically, genderfixed sex roles were determined on 'natural' and 'acceptable' specific sexual and domestic behavior of the two predominant genders, namely, females and males. However, with the advent of 1970's social constructionist movements and feminism, explicit gynocentric discourses on sexual violence may have inadvertently made it difficult to deal with the holistic nature and extent of CSE (Pilgrim, 2017). Whilst feminist discourses have heightened gender-sensitivity in respects of bifurcating a gendered demarcation of offender and victim profiles (e.g. Kelly's 1988 Continuum of Sexual Violence), young male victim-specificities/sensitivities become gender-pluralised within dominant CSE discourses.

In the exploration of specific discourse on young male victims, the selected theoretical frameworks needed to be able to confidently facilitate a platform for (expected) minority discourses in CSE policy perceptions to be heard and understood. The selected theories included Turner's (1969) theory of Liminality and various works of Foucault (1976, 1977, 1991) on childhood sexuality, surveillance and governmentality, to gain a 'deep-dive' into the existing network of language and classification in CSE policy since 2000. Whilst some post-structuralists may reject the idea of structuralism, Bevir (2010) observes that post-structuralism preserves many elements of structuralism including differential theory of meaning. However, the essential focus of this study was for the hybridity of theories to optimally deconstruct social concepts within policy perceptions. Fanner (2019) proposed that Foucauldian concepts such as governmentality is only 'knowable' or observable if there is an established network of language and classifications to describe it; thus, the need for structuralist theory inclusion.

Turner's (1969) theory of Liminality concentrates on the space balanced or suspended between two states, conditions, points or descriptions that do not have a particular point of reference (Harter, 2016). It is in this suspension that Turner defines liminal entity, a term used to describe the 'in between' phases of social positions or cultural conditions that are 
assigned by language and classification, creating uncertainty. In order to deal with liminal entities, closely related language and classifications may be used in replacement. For example, a young male who is considered invulnerable to CSE due to his perceived maturation and physical stature, yet is assessed to be a victim, may be portrayed as a victim against the same expectations of the majority of victims, e.g. females.

To understand the governmentality of CSE in the present day, Foucault's (1976) concept of the 'qualified speakers' of childhood sexuality was used; borne out of the unintended sexual censorship of the triple edict of 'taboo, non-existence and silence', describing the Victorian 'Repressive Hypothesis'. The repressive hypothesis concerned children as “...precious and perilous, dangerous and endangered sexual potential" (Foucault, 1976, p.104) but Foucault noted that this concern centrally-focused on the intensity and attention paid to it rather than its frequency. The qualified speakers (e.g. today's child welfare professionals) became the state's subjects within disciplinary power-knowledges, such as medicine or religion, to perform what Foucault (1991) later termed governmentality, which produces selfgovernance/'ethics of the self' in ultimately protecting children from sex (Foucault 1977). Foucault (1988) suggested that the ethical conduct of subjects within power-knowledge institutions was constructed through the development of selfknowledge. Foucault believed that self-knowledge was discursively produced and operated through selected 'games of truth', comprising of adherence to disciplinary rules in the production of truth, resulting in power-knowledge i.e. dominant discourse.

This article presents the modern-day concept of Foucault's (1976) 'qualified speaker of childhood sexuality' selfknowledge through two ethical domains: the ethical substance and ethical work (Dean, 2010). Foucault considered the ethical substance, or problematisations, to be characterised through selected specific moments and situations that require governance as the first stage of the analytics of governance, thereby creating forms of power-knowledge, through discursive practices (Dean, 2010). Once, the ethical substance has been identified, Arribas-Allyon and Walkerdine (2008) consider the ethical work to be acts or practices of governance i.e. the rationality of ones' work or conscious goal.

\section{Findings}

\subsection{Ethical substance of CSE policy}

The emerging ethical substance appeared to have tensions between what was intelligible, manageable as well as governable within CSE policy. The 'ethical substance' of young male inclusion was not particularly clear-cut, but statements were selected that articulated the moral domains and judgements that facilitated their circumstances, resulting in their construction and positioning (Arribas-Allyon and Walkerdine, 2008). To illuminate this, the moral domains and judgements were based on the three processes of the objectification of the individual as outlined in Foucault's (1977) Discipline and Punish, including: Beginning to Define the Problem of 'Child Sexual Exploitation' (hierarchical observations); young males not perceived as to meet the traditional profiling of victims (normalising judgements), and the risk of CSE to young males who have sex with other males (examination).

\subsubsection{Hierarchical observations: defining child sexual}

exploitation. The first process of the objectification of the individual is the hierarchical observations, whereby the desired disciplinary power is achieved through optimal disciplinary apparatus that can observe, everything, constantly, as a central point, through a single gaze, so that problematisations are identified with ease. Participants were asked to consider how CSE policy, the government's optimal disciplinary apparatus, affected their day-to-day work, yet without reciting official policy definitions. Defining the problem of CSE in interviews was often ambiguous, vague or broad, or even not previously considered. Participants understood CSE from a narrow/defined focus of chronological age difference between the offender and victim, to wider and structural considerations, such as the growing trend of sexualisation of youth culture. Particularly, many participants expressed perceptions that reflected the 'history of the present', especially those who had worked in child protection for many years, whereby the knowledge of CSE lacked historical surveillance but had since come into 'being'. This 'history of the present' perception perhaps reflects an unravelling of the historical sexual censorship in 'spoken' discourse. The idea that CSE policy had now created greater surveillance meant that Foucault's claim that this type of hierarchical observation becomes a main economic operator as '... an internal part of the production machinery and as a specific mechanism in the disciplinary power' (1977; p.175).

...my understanding of CSE has developed...Um, when I became a social worker in 1985, I had no idea what CSE was, but um... and most of the people didn't. Um, and I would say up until 2009 uh, even the government still called it uh...child prostitution. Um, but if you think about it, in 1984, '85 when I started working, um, people were only just coming to terms with the whole idea of sexual abuse. So...knowledge has developed over 
time...understanding has...changed. (Regional Strategic Policy Educator)

Defining the problem also took into consideration the wider, cultural perceptions of sexual permissiveness of the growing threat of the over-sexualisation of young people which was yet to establish how this impacted on CSE, rendering this threat ungovernable. When considering this over-sexualisation, participants often defaulted to using young females, at the cusp of puberty and start of their adolescence, as examples, epitomising dominant, spoken discourse.

...I think there is something about the over-sexualisation of young people. I think there is something about the permissiveness of today's society that has created some... a Pandora's box has been opened and we don't fully understand all this yet... Whilst I defend absolutely the right of young people to dress how they want to dress and express themselves...I'm old enough to be able to say I think if my 12-or 13-year-old...daughter went out dressed looking like a 17-or 18-year-old, I wouldn't allow her out. (CSE Statutory Policy Enactor)

In addition to the range of definitions offered, perturbations and vocalised pauses were common in responses to interview questions on how participants defined CSE in their work. The theory of Liminality (Turner, 1969) can be used to demonstrate how young males are left within the betwixt and in between of existing CSE vocabulary within policy, therefore limiting what is knowable, manageable and governable about them, such as the statement below on defining young males within CSE.

No, not in a small sentence, no. Not really, because...there's a lot of different aspects to it. Um...males generally, um, offering services, err, such as, err, whether it be transport or, um, facilities such as flats, et cetera, um, and then offering them items such as alcohol or drugs. It's the usual stuff, you know what I'm talking about. (CSE Statutory Policy Enactor)

6.1.2 Normalising judgments: a gynocentric focus. The second process of the objectification of the individual are the normalising judgments, which are based upon what has been observed through the hierarchical observations. The judgments create a sense of reality that identify problems requiring governing. This process emphasises the exercise of disciplinary power and the resistance-to-power, producing epistemic transformations, resulting in new ways of thinking, and therefore, governing. One policy maker identified that $21^{\text {st }}$ century policy developments had taken a dominant female, or gynocentric, focus, whilst another policy influencer felt that inadequate attention was due to young males not making the 'perfect victim'.

It's still...under recognised and under catered for...in 2011, it was predominantly focused on...teenage white girls especially. And it became clearer...that there were girls beyond those communities that are being affected as well. We only really slightly touched on the issue of boys in the initial action plan. I think...that was a weakness. (National Policy Maker)

...I've not seen a big drastic change and I've not seen lots of people suddenly saying...that, um, boys and young men are being exploited and we've got to start addressing this.'...I sometimes wonder whether boys don't make the perfect victim? (National Policy Influencer)

Despite overt gynocentric perceptions of policy, participants were not able to give clear reasons for why young males were not judged in the same way as young females, but three discourses emerged that explained these differences: 1) lack of professional experience, 2) victims being a sexual minority, and; 3) LGB\&T+ communities, homophobia and CSE. Many participants felt that they lacked the necessary professional experience of understanding and working with young males, and this was often found in interviews with participants who also gynocentrically problematised CSE. One participant notably highlighted that whilst the legality of CSE for all genders was clear, that young males, especially those who identified as GBT had a very different life course experience. They explained that young GBT males had different experiences around sexual safety and difficult life course issues with regards to sexual vulnerabilities of CSE and exposure to the LGB\&T+ scene, much later than their heterosexual peers so therefore would not be 'judged' in the same way.

I think there's a sort of car crash of issues that come together, potentially for some young LGB and T people, and those issues are...not an equal playing field in terms of safety...Right now it is...legally it is more of an equal playing field, but that's only... very recent. So if...you sort of come away from the CSE and just come into sort of how you expect ordinary kind of young people to ordinarily grow up, and the things...the stages you go through, the things you experience are later... and in different communities or scenes. (LGB\&T+ Voluntary Sector Worker)

\subsubsection{Examination: insightfulness into problematisation}

of young male victims. One of the most varied corpuses of statements came from the third and last key process of the 
objectification of the individual: the examination. Foucault (1977) defined examination as a highly ritualistic mechanism by firstly differentiating individuals from one another through visibility and, secondly, judge individuals, classifying them through surveillance. Bearing in mind that the hierarchical observations and normalising judgement processes inadequately captured the risks, perceived sexual exploitation experiences and help-seeking behaviours of young males, the examination became harder to identify within the interview transcripts. Whilst a distinct lack of male-centric CSE vocabulary has not developed within policy, during the data collection, a retrospective incident arose regarding a 12-yearold male, seen by several participants, in his school uniform, in a well-known sex work geography as described below.

...I found a 12-year-old lad down there in his uniform...Um, you know, when we like found him, there was loads of men around him...As soon as we turned up they all vanished...I said, "Fucking hell [colleague]. Is that a kid there?" You know perhaps double...take...So I walk passed and I said, "Yeah"... "Are you okay mate?"... He went "fuck off"...there was another lad who was with him who sort of got a grip of him. This other lad was a bit older. He's about 23...Um they was clearly like together...[colleague] phoned the police and we reported it...They answered the phone. "What do you mean, that rent boy?"...that's what they said. "It's a fucking 12-year-old kid". Obviously, we complained about that and got that sorted. (Voluntary Sector Outreach Worker)

Whilst this was of great concern to a child at immediate risk, there is a crucial examination issue occurring by mainstream services with statutory child protection responsibilities using the colloquialism of 'rent boy', echoing older terminology once pre-2000. It was common for other, older, terms to be afforded to describe the sexual exploitation experiences of young males such as 'frequent'. This is not too dissimilar from then-defunct legislation, the Sexual Offences Act 1967, defining male involvement in prostitution as problematic if they 'persistently solicited' a public place for immoral purposes.

... I've had young boys that frequent the gay village, that

have met... males... (CSE Statutory Policy Enactor)

Both of these examples illustrate how language was used to 'examine' young males affected by CSE, reflecting preCSE language and classifications prior to the epistemic transformations of policy developments from 2009 (DCSF, 2009).
6.1.3 LGB\&T+ communities, homophobia and CSE. With the lack of awareness of existing specific male advice within CSE policies, many participants did not feel able to discuss LGB\&T+ issues, due to fear of being perceived as homophobic and risk of conflating homosexuality with paedophilia, including noticeable perturbations and vocalised pauses. A minority of participants who either identified as LGB\&T+ and/or worked for an LGB\&T+ organisation, spoke more freely about the perceived risks the LGB\&T+ scene posed to young males such as 'chemsex' or polysubstance misuse during sexual activity. One voluntary sector manager perceived that a community approach to dealing with CSE within the LGB\&T+ communities was the only way forward in addressing CSE, but such communities were too frightened due to historical conflations between homosexuality and paedophilia.

I think...uh...I sometimes wonder if it's...one of those kind of it happens in everybody else's community and not ours...I sometimes wonder if there is something about the uh, you know, the red top newspapers link that they have between paedophilia and homosexuality... if we start talking about it then everybody will think that we're paedophiles. You know...my argument has always been yeah but if you don't talk about it we'll never get rid of that myth. (Voluntary Sector Manager)

Overall, national policies were perceived to be dominantly heterocentric and often young males, especially young GBT males, were missing from the policy problem.

I think there are blanket issues...about being knowledgeable and comfortable with an identity (LGBT) and context (chemsex, hook-up apps etc) so that young men feel safe to speak up. This needs to be reflected in the 'public story' about consent/exploitation so young men can see themselves accurately... And we need to see how those issues of consent play out for young men in ways that might be different to young women...but you may need to add onto that with young gay people in terms of the context in which it's happening, and I think that's probably what mainstream CSE is not doing. (LGB\&T+ Voluntary Sector Worker)

\subsection{Ethical work of CSE policy}

In Discipline and Punish, Foucault (1977) understood that the conscious goal of the techniques of disciplinary power was to shape, mould, discipline and control societies and as applied to CSE, can be illustrated through national policies and in particular, national action plans or strategies. Overwhelmingly, throughout the data collection, participants perceived young male victims not to 'fit' the over-arching, 
gynocentric, rationality of the contemporary CSE policy development. The findings within the ethical work present two levels of data, firstly the national policy intentions/'backdrops', and secondly, how young males 'fitted' within local policy implementation in response to national policy. Since 2000, CSE policy has been through turbulent (re-)development, often with new CSE policies replacing old policies without reference backwards. With the government's (re-)commitment in 2011 to 'tackling' CSE, an observed fragmentation of children's policy meant that the ethical work of youth policy, especially CSE, was severely diluted due to six government departments being involved.

...there's a problem with children's policy now in that it's being fragmented so that Home Office leads on CSE and MOJ [Ministry of Justice] leads on justice. DLCG [Department for Communities and Local Government] leads on...troubled families. DCMS [Department for Digital, Culture, Media \& Sport] leads on access to pornography by underage kids which is a huge influence...then DfE [Department for Education] has still got some child protection responsibilities but it's the grey area between that and who need care [e.g. Department of Health] and various other things. So the whole lot is now rather disparate...the other thing is youth policy which is the biggest disaster of the lot...so you've got six departments. (National Policy Maker)

6.2.1 CSE policy 'backdrops'. Participants felt that the national policy intentions formalised the work that was required of them, especially through political contexts and surveillant techniques. Whilst the Violence Against Women and Girls (VAWG) agendum has sensitised sexual violence to fixate upon gender 'roles' within abuse, participants often perceived that this type of framing or 'backdrop' negated young males as victims.

You know...if you think about...the main policy in this country that's leading any work with young people around CSE...is the...violence against women and girls agenda. Because the very...the whole...the label itself is negating young men, you know, so what's missing from policies is the words 'young men'. (Voluntary Sector Manager)

Panoptic culture, competing with the VAWG discourse, played a large role in the ethical work of CSE policy. Participants perceived the statutory requirements placed on local authorities to safeguard children did not suit adolescents and were inadequate to reducing their contextual risks to abuse (usually, outside of the home); so much wider surveillant techniques were encouraged and implemented to go beyond the realms of child-facing welfare services.

So, we work as closely with our...strategic housing colleagues, our legal colleagues, our licensing colleagues, for taxi drivers, for takeaways...we work with our hotels...so that we understand that child sexual exploitation can come through many other means and is linked with many other crimes. (Regional Strategic Policy Actor)

In order to counter the strong-hold of the VAWG agenda with CSE policy and increased surveillance, the local case study area had commissioned a specialist young male-CSE organisation to review their service and provide staff training but the organisation was overwhelmingly perceived negatively across all participants within the case study. There were two broad negative perceptions of this organisation. Firstly, due to their lack of evidence-based knowledge on young male-specific assessment and interventions, with a sole and repeated reliance of the CSE proverbial 'it's not just girls' and secondly, the lack of quality assurance in assessing this organisation's expertise against any national standard.

They have an agenda...that...generates a huge amount of money for them...they set themselves up as experts and...cornerstone of good practice. But...the three or four...case studies that [they] start out with in the morning, basically, every case study was up to the point that ORGANISATION got involved, everything was shit. I'd gotten it after an hour that's it's not just girls. I understood it extremely well after two hours that it's not just girls, and I wanted to punch his lights out after three hours. (CSE Statutory Policy Enactor)

6.2.2 Local joined-up working. One of the key ethical works of CSE policy has been the encouragement of joined-up working in local areas, however, dissonance became apparent within co-existing perceptions of national policy makers and policy enactors of how young males were considered within CSE policy. Whilst CSE policies are gender neutral in the main, specific attention had been drawn to young males within the present policy at the time of data collection (e.g. DCSF, 2009) yet policy enactors were either not aware of this or did not perceive it to be in-depth enough.

There needs to be a lot of development around boys and young men in child sexual exploitation. Um, I think sometimes...it can be difficult... because of the number of young men that are brought to our attention...it's trying to develop those services when we've only got minimum numbers. (CSE Statutory Policy Enactor) 
The existing CSE policy development towards young male victims resulted in counter-rationales or resistance for the need to recognise the emerging (minority) discourses on young males as victims of CSE by claiming young males as 'too specialist' by some participants. One statement particularly illuminated this resistance by stating the actuality of sexual activities within CSE to go beyond 'traditional' heterosexuality, particularly noting the use of the verb 'had' for vaginal sex versus the adjective 'involved in' for anal sex.

...I would normally ask... "What kind of sex have you had? Was that anal or vaginal?"...So... a young woman perhaps has only had vaginal sex, I may offer a chlamydia and gonorrhoea screen. Um, a young man who's, um, involved in an anal sex, then I wouldn't even bother offering that. I'd get them to [Genito-Urinary Medicine] to...because that's not something I can do within my remit...It's becoming too specialised. (CSE Policy Enactor (Health))

Many perceptions of participants identified that frequently and only when voluntary sector organisations, who worked closely with the LGB\&T+ community, were brought on board with the ethical work of CSE risk assessment, would a young male's 'risk' be governed. Two statements below illustrate how statutory 'qualified speakers' dealt with potential young male victims.

.... and at that point it's...like, is this person at risk, or are they just exploring their sexuality? And sometimes in most of those cases the police investigation stops, so Social Services downgrade it.

\section{(LGB\&T+ Voluntary Sector Worker)}

...the social workers are scared of challenging that because they don't want to be seen as being homophobic...I can list you...probably...about 15 people that I know of that need the social worker, who are under 18, who I was meeting in outreach regularly...but they won't pick up the cases still. (Voluntary Sector Manager)

In addition, negative perceptions from within the voluntary sector participants emerged of the ethical work carried out by statutory services with regards to young male victims. The statement below demonstrates a distinctly different professional language used to young female victims, reflecting a continual theme of gynocentricity and heterocentricity, adopting a more male-gender-fixed sex role and agency-based question.

They'd go out and then ask them outright, "Are you involved in sex work?" Because they don't see it as CSE, like they would with the female necessarily, you know.
"Are you involved with sex work?" they'd say no, so they close the case within an instance of asking them in front of their grandma and they said no so they just close the case. (Voluntary Sector Manager)

\section{Discussion}

Using alternative critical theories to understand how young male victims are presented within expert discourses in CSE policy and professional practice has proved a worthy enterprise. Paskell (2012) observed there has been a significant implementation of CSE policy (DfE, 2011) increasing from one quarter (Jago et al., 2011) to two-thirds, potentially leading to greater identification of young males. At least one of third of CSE victims are male, which is supported by both policy (e.g. DCSF, 2009) and empirical research (Cockbain, Ashby and Brayley, 2015) so young males make up a significant population of those affected by CSE. This study reflects the policy-practice (and vice versa) realities of professionals working with young males in a geographical area with a well-developed CSE response to the Action Plan (DfE, 2011), through examining their perceptions by sensitively 'unpicking' the self-knowledge within expert discourses within the previously observed paradoxical, yet highly-charged, contextuality in the governmentality of CSE.

The ethical substance of CSE, taking Foucault's objectification of the individual, demonstrated an uneasiness in 'fitting' young males into existing victim discourses. The reality of most CSE practice, within the sample of participants, showed that young males are considered an afterthought or an addition to the primary and central focus on young female victims. Even on asking how participants defined young males within CSE was met with perturbations and vocalised pauses. With the many government departments involved, the change from statutory CSE guidance to a CSE action plan, the increasing sexualisation of youth culture, the minimal policy presence of young males, together, has somewhat created heterogenous perceptions within professional practice that has ultimately led to a decreased awareness / confidence in working with young male victims, including LGB\&T+ community fears of (re-)conflating homosexuality with paedophilia. Overwhelmingly, the perceptions of many interview participants often associated any depth on sexuality/sexual identity development in male CSE with the 'exploration' and/or (potential) self-identity as GBT+, rather than separating the gender identities of both perpetrators and victims of young males' experience of CSE and their sexual identity (whether self-reported by young males or perceived by the participant). This 'automatic' or immediate association or conflation of gender/sexual identity (e.g. GBT+) and CSE when discussing sexuality/sexual identity development in 
depth may be unique to this study. The findings in this study (and the previous, published literature) does not establish whether young GBT+ males make up the majority of cases but this latter point brings into question how heterosexual/'straight' young male victims may navigate their experience(s) when engaging with CSE practitioners/services.

The policy reality of young male sexual exploitative experiences, disclosure needs, help-seeking behaviours and support needs is limited and are in fact perceived by practitioners to be far more granular within the previous literature and this study. This study has identified a perceived lack of policy 'capture' of male-specific CSE experiences (particularly GBT), demonstrating that not all CSE victims are 'equal' practically-morally within societal structures yet are legally, resulting in inadequate policy responses. The three main considerations for young males, outlined in the DCSF (2009) guidance, on surveillance, service engagement and disclosure would appear consistent within the statutory services but not for the voluntary sector. There appeared to be a correlative perception of experience with young male victims and the ability to meet their perceived needs, including professional fear of homophobia and uncertainty in dealing with 'sexuality exploration' versus sexual exploitation.

The ethical work of CSE was perceived to be underpinned through two main policy drivers including panopticism and the VAWG agenda, especially within the DfE (2011) Action Plan. Through both these competing policy 'backdrops', young males potentially became lost or became assembled awkwardly in CSE policy responses, with local areas attempting to panopticise their entire geographies, whilst maintaining centrality to young females due to the perceived low numbers of young males 'seen' in services. The changes in how CSE has been conceptualised from child prostitution to child sexual exploitation quite rightly reflects a modern aspiration of preventing any kind of sexual harm towards children. Within this aspiration, however, young males are perceived as complex, or at worst, 'too specialist' within VAWG-dominant joined-up working arrangements, especially with emerging types of CSE reflecting non-heterosexuality/-normativity such as chemsex.

The LGB\&T+ voluntary sector was overwhelming perceived to be integral to comprehensive CSE policy implementation and as a significant voice in 'joined-up' working with statutory services. The use of a male-specific CSE organisation was perceived as poor by all participants in the local case study and brings into question how such organisations which claim to be 'expert' in specialist areas of child protection can and should be quality assured.
The use of Liminality theory has identified that current CSE language and classification is under-developed specifically to define and describe young males, with many participants struggling to apply mainstream CSE vocabulary to young males due to gynocentric connotations. Building upon Melrose's (2013) critical discourse analysis of CSE, vocabulary used to describe young male victims' experiences in this study were either missing, problematic or relied upon historical terms of reference. Regardless of the mainstream epistemic transformations of CSE language to render any agency (e.g. Melrose, 2013), young males, in fact, are regarded with more linguistic agency than their female peers. For example, labelling the behaviour of a potential young male victim as a 'rent boy' or 'being involved in sex work?' affords him significant sexual agency, as well as/and labelling potential groomers, almost double their age, in the somewhat benign concept of 'lad' (as reported in this study) leads to perceptions of his invulnerability. Particularly interesting use of adjectives such as 'to frequent' and 'involved in anal sex' was observed in this study. These linguistic scenarios perhaps echo Green's (2005) observations of historical gender-fixed sex roles and identify further development of acceptable vocabulary for young GBT males.

\section{Contemporising this study's findings to the current policy and public discourse on CSE}

Despite the advent of national male-specific guidance within CSE policy (i.e. DCSF, 2009) that was current at the time of data collection, practitioners remain left at large to accommodate young males in their identification, screening, assessment and engagement. It is particularly worthwhile pointing out that no participant had spoken about the DCSF (2009) guidance on young males. Despite the national malespecific guidance, the policy-practice realities for young males is varied in how they are discursively constructed within professional practice. Three future policy considerations are identified from the results of this study:

1) Gender-neutral CSE policy fully encapsulates the safeguarding and protection of all children, but whilst sexual exploitation experiences, disclosure needs, help-seeking behaviours and support needs are different between genders, greater male-specific advice/models / agendas must increase. Monitoring of gender-specific inclusions should take place in terms of its understanding, implementation and application in practice.

2) Policy constructs that are essentially 'at risk' of CSE, so careful consideration on how victims are 
presented must ensue, especially with regards to how professionals access gender-specific guidance.

3) The development of greater, acceptable vocabulary on childhood sexuality and CSE must start to consider what is deemed healthy/positive sexual(ity) development to allow professionals and young people to distinguish between CSE and healthy sexuality.

The authors cogently propose that with the (re)presentation of gender-plurality/neutrality of the current CSE policy frameworks (e.g. DfE, 2017; Home Office, 2021), the findings of this article remain of great relevance. Further research should be conducted, however, to explore the construction of young male victims within this new policy discourse including its enactment into practice. Future research should also take into account the more recent, fastmoving pace of public and professional awareness and understandings of other CSE-related phenomena, such as criminal exploitation (e.g. the County Lines phenomenon), whereby there is greater delineation of gendered understandings of how young males and females are classified in relation to sexual or criminal exploitation.

\section{Limitations}

Five main limitations are considered with this study. Firstly, the findings present the difficulty of generalisability. Importantly, however, the findings illuminate genealogicallyspecific contexts on the discourse on young males in CSE policy. The findings also offer transferability to future youth policy that require taking in the sexual exploitation experiences, disclosure needs and help-seeking behaviours of young males. Secondly, the non-probability approach to sampling may have hindered obtaining a holistic picture of what may have been happening in the selected case study area for young males, particularly with a well-developed social policy response to CSE that had previously been subject to an external review of its young male inclusion. This external review potentially skewed the interview participants' responses by offering discussion points with recent rehearsal. Thirdly, the fieldwork was conducted in 2015, six years after the introduction of the DCSF (2009) guidance and two years before it was superseded by the gender-neutral DfE (2017) Child sexual exploitation: definition and guide for practitioners. Whilst the data presented in this study is policycontext specific, it may not reflect contemporary practices under the DfE (2017) guidance. Fourthly, the first author is a registered health visitor and (at the time of data collection) a doctoral researcher. This dual identity may have created an imbalance of perceived power, authority or surveillance on
CSE knowledge by others, as a peer within safeguarding, within the data collection and analysis. Finally, the lack of prescription in the methodological advice from ArribasAllyon and Walkerdine (2008) on conducting a Foucauldianinspired discourse analysis potentially means that important statements are missed from the corpus selected for analysis.

\section{Conclusion}

Overall, this study has facilitated a platform for an array of the expert discourses from professionals' perceptions of young males within CSE policy and has valued these perceptions, qualitatively, without presenting a dichotomising predicament for what is right or wrong way to deal with CSE. This study has identified young male victims to have been social constructed in the 'shadows' of their female peers, perhaps, as a policy afterthought with consequential professional practices. Essentially, young male victims have been implicated through this gendered conceptualisation and are assembled awkwardly on the surface of ethical and moral activities within mainstream CSE discourse.

The currently understood theory and conceptualisation of CSE is a developing social phenomenon, and, due to its nature and process within the modus operandi of child sex offenders, makes CSE a 'hard-to-reach' social problem to investigate. As a direct result of the study's findings, further research should investigate the development of a policy intervention(s) that pay attention to increasing accessible and acceptable CSE vocabulary in order to expand the recognition, detection, assessment and effectiveness of preventing further sexual harm to young male victims. The authors postulate that while young males are justified, and significant, victims of CSE, they become lost in the gynocentric milieu of professional practice and social policy responses and it is concerning their current policy presence (DfE, 2017; Home Office, 2021) has significantly pluralised into near-complete gender-neutrality.

\section{References}

Arribas-Ayllon, M. and Walkerdine, V. (2008) 'Foucauldian Discourse Analysis' in Willig, C. and Stainton-Rogers, W. (eds) The SAGE Handbook of Qualitative Research in Psychology. Great Britain: Cromwell Press. pp.91-108.

Attwood, F. (2010) 'The Sexualisation of Culture' in Attwood, F. (ed.) Mainstreaming Sex. London: I. B. Tauris \& Co. Ltd. 
Barnardo's (2011) Puppet on a String: The Urgent Need to Cut Children Free from Sexual Exploitation. Available at: https://www.bl.uk/collection-items/puppet-on-a-stringthe-urgent-need-to-cut-children-free-from-sexualexploitation (Accessed: 24 May 2021).

Bevir, M. (2010) 'Rethinking governmentality: Towards genealogies of governance', European Journal of Social Theory, 13(4), pp.423-441.

Bingham, A., Delap, L., Jackson, L. and Settle, L. (2016) 'Historical child sexual abuse in England and Wales: the role of historians', History of Education, 45(4), pp.411429.

Brayley, H., Cockbain, E. and Gibson, K. (2014) Rapid evidence assessment - the sexual exploitation of boys and young men Available at: https://www.nuffieldfoundation.org/sites/default/files/files/ cse young boys summary report.pdf (Accessed: 18 April 2021).

Calder, M. C. and Archer, J. (2016) Risk in Child Protection. Assessment in Childcare. Great Britain: Jessica Kingsley Publishers.

Carey, L. (2021) Re: BLAST Project. [Email]. Message to Michael Fanner. $8^{\text {th }}$ June 2021. [cited $8^{\text {th }}$ June 2021]. Stored on Michael Fanner's university email system. Personal communication.

Cockbain, E., Ashby, M. and Brayley, H (2015) 'Immaterial Boys? A Large-Scale Exploration of Gender-Based Differences in Child Sexual Exploitation Service Users', Sexual Abuse: A Journal of Research and Treatment, 29(7), pp.658-684.

Cockbain, E. (2013) 'Grooming and the 'Asian sex gang predator': the construction of racial crime threat', Race \& Class, 54(4), pp.22-32.

Coy, M. (2016). 'Joining the dots on sexual exploitation of children and women: A way forward for UK policy responses', Critical Social Policy, 36(4), pp.572-591.

Crawley, M., Roberts, P. and Shepherd, W. (2004) Taking
Stock: Children and Young People at Risk of or Involved in Abuse through Prostitution within Stockton-on-Tees. Barnardo's.

Dean, M. (2010) Governmentality. Power and Rule in Modern Society. Second Edition. Wiltshire: Sage.

Department for Children, Schools and Families (DCSF) (2009) Safeguarding Children and Young People from Sexual Exploitation: Supplementary Guidance to Working Together to Safeguard Children. London: Department for Children, Schools and Families.

Department for Education (DfE) (2017) Child sexual exploitation: definition and guide for practitioners. London: Her Majesty's Stationary Office.

Department for Education (DfE) (2011) Tackling Child Sexual Exploitation Action Plan. London: Her Majesty's Stationary Office.

Department of Health (DH) / Home Office (2000) Safeguarding Children Involved in Prostitution. Supplementary Guidance to Working Together to Safeguard Children. London: Her Majesty's Stationary Office.

Donovan, C. (2014) The Ace Project: Developing an Agenda for Change in the North East and Beyond for Young LGBTQ People and Child Sexual Exploitation. Sunderland: University of Sunderland.

Fanner, M. J. (2019) Professionals' perceptions of young males in child sexual exploitation policy: a critical policy genealogical analysis. $\mathrm{PhD}$ thesis, University of Greenwich. Available at: https://gala.gre.ac.uk/id/eprint/34342/ (Accessed: 8 November 2021).

Foucault, M. (1991) 'Governmentality' in Burchell, G., Gordon, C. and Miller, P. (eds) The Foucault Effect. Studies in Governmentality with Two Lectures By and An Interview with Michel Foucault. United States of America: The University of Chicago Press, pp.87-104. 
Foucault, M. (1988) 'Technologies of the Self’ in Martin, L., Gutman, H. and Hutton, P. Technologies of the Self. A Seminar with Michel Foucault. United States of America: Tavistock Publications, pp.16-49.

Foucault, M. (1977) Discipline and Punish. Harmondsworth: Penguin.

Foucault, M. (1976) The History of Sexuality. Volume 1: An Introduction. London: Penguin Books.

Garland, D. (2014) 'What is a 'history of the present'? On Foucault's genealogies and their critical preconditions', Punishment \& Society, 16(4), pp.365-384.

Green, L. (2005) 'Theorising Sexuality, Sexual Abuse and Residential Children's Homes: Adding Gender to the Equation', British Journal of Social Work, 35, pp.453-481.

Hallett, S. (2015) “'An Uncomfortable Comfortableness': 'Care', Child Protection and Child Sexual Exploitation', British Journal of Social Work, pp.1-16.

Harter, N. W. (2016) Foucault on Leadership. The Leader as Subject. Routledge.

Her Majesty’s Government (2006) Working Together To Safeguard Children: A guide to inter-agency working to safeguarding and promote the welfare of children. London: The Stationery Office.

Hicks, L. (2014) 'Responding to adolescent risk: continuing challenges' in Blyth, M. (ed.) Moving on from Munro. Improving children's service. Bristol: Policy Press.

Home Office (2021) Tackling Child Sexual Abuse Strategy. London: Her Majesty’s Stationary Office.

Hudson, P. and Rivers, I. (2002) Men \& Boys. Selling Sex in the Bradford District. Social Inclusion \& Diversity Paper No 1. Research Into Practice. Leeds: York St John College of the University of Leeds.

Jago, S., Arocha, L., Brodie, I., Melrose, M., Pearce, J. and Warrington, C. (2011) What's going on to Safeguard Children and Young People from Sexual Exploitation.
How local partnerships respond to child sexual exploitation. Luton: University of Bedfordshire.

Jones, R. (2014) 'Child protection: 40 years of learning but where next?' in Blyth, M. (ed.) Moving on from Munro. Improving children's service. Bristol: Policy Press.

Kelly, L. (1988) Surviving Sexual Violence. Minneapolis: University of Minneapolis Press.

Lewis, J. and McNaughton Nicholls, C. (2014) 'Design Issues' in Ritchie, J., Lewis, J., McNaughton Nicholls, C. and Ormston, R. (eds) Qualitative Research Practice. A Guide for Social Science Students \& Researchers. Second Edition. Great Britain: Sage.

McEvoy, P. and Richards, D. (2003) 'Critical realism: a way forward for evaluation research in nursing?', Journal of Advanced Nursing, 43(4), pp.411-420.

McNaughton Nicholls, C., Harvey, S. and Paskell, C. (2014) Gendered perceptions: What professionals know about the sexual exploitation of boys and young men in the UK. London: Barnardo's.

Melrose, M. (2013) 'Child Sexual Exploitation - A Critical Discourse Analysis' in Melrose, M. and Pearce, J. 2013. Critical Perspectives on Child Sexual Exploitation and Related Trafficking. London: Palgrave.

Mills, S. (2004) Discourse. Great Britain: Routledge.

Paskell, C. (2012) Tackling Child Sexual Exploitation: Helping Local Authorities to Develop Effective Responses. Ilford: Barnardo’s.

Pawson, R. (2006) Evidence-Based Policy: A Realist Perspective. London: Sage.

Petrie, S. (2012) 'Violence, sex and the child' in Brown, J. M. and Walklate, S. L. Handbook on Sexual Violence. Great Britain: Routledge.

Pilgrim, D. (2017) 'The Perils of Strong Social Constructionism: The Case of Child Sexual Abuse', Journal of Critical Realism, 16(3), pp.268-283. 
Phoenix, J. (2002) 'In the name of protection: youth prostitution policy reforms in England and Wales', Critical Social Policy. 22(353), pp.353-375.

Plummer, K. (2003) 'Introduction, representing sexualities in the media', Sexualities, 6(3-4), pp.275-276.

Ritchie, J. and Spencer, L. (2003) 'Qualitative Data Analysis for Applied Policy Research' in Ritchie, J. and, Lewis, J. (eds) Qualitative Research Practice. London: Sage Publications.

Scott, S. and Skidmore, P. (2006) Reducing the Risk: Barnardo's Support for Sexually Exploited Young People - A Two-year Evaluation. London: Barnardo’s.

Swann, S. and Balding, V. (2002) Safeguarding Children Involved in Prostitution. Guidance Review. London: Department of Health.

Taylor, C. and White, S. (2001) 'Knowledge, Truth and Reflexivity: The Problem of Judgement in Social Work'. Journal of Social Work, 1(1), pp.37-59.

Turner, V. (1969) 'Liminality and Communitas' in Turner, V. (ed) The Ritual Process: Structure and Anti-Structure. Chicago: Aldine Publishing. pp.94-113.

Walker, D (2014) Findings of Scoping Exercise into Practitioners knowledge of Child Sexual Exploitation of LGBT Young People in the North East. Northern Rock Foundation.

Wong, G., Greenhalgh, T., Westhorp, G., Buckingham, J. and Pawson, R. (2013) 'RAMESES publication standards: realist synthesis', BMC Medicine, 11(21), pp.1-14. 
Appendix I

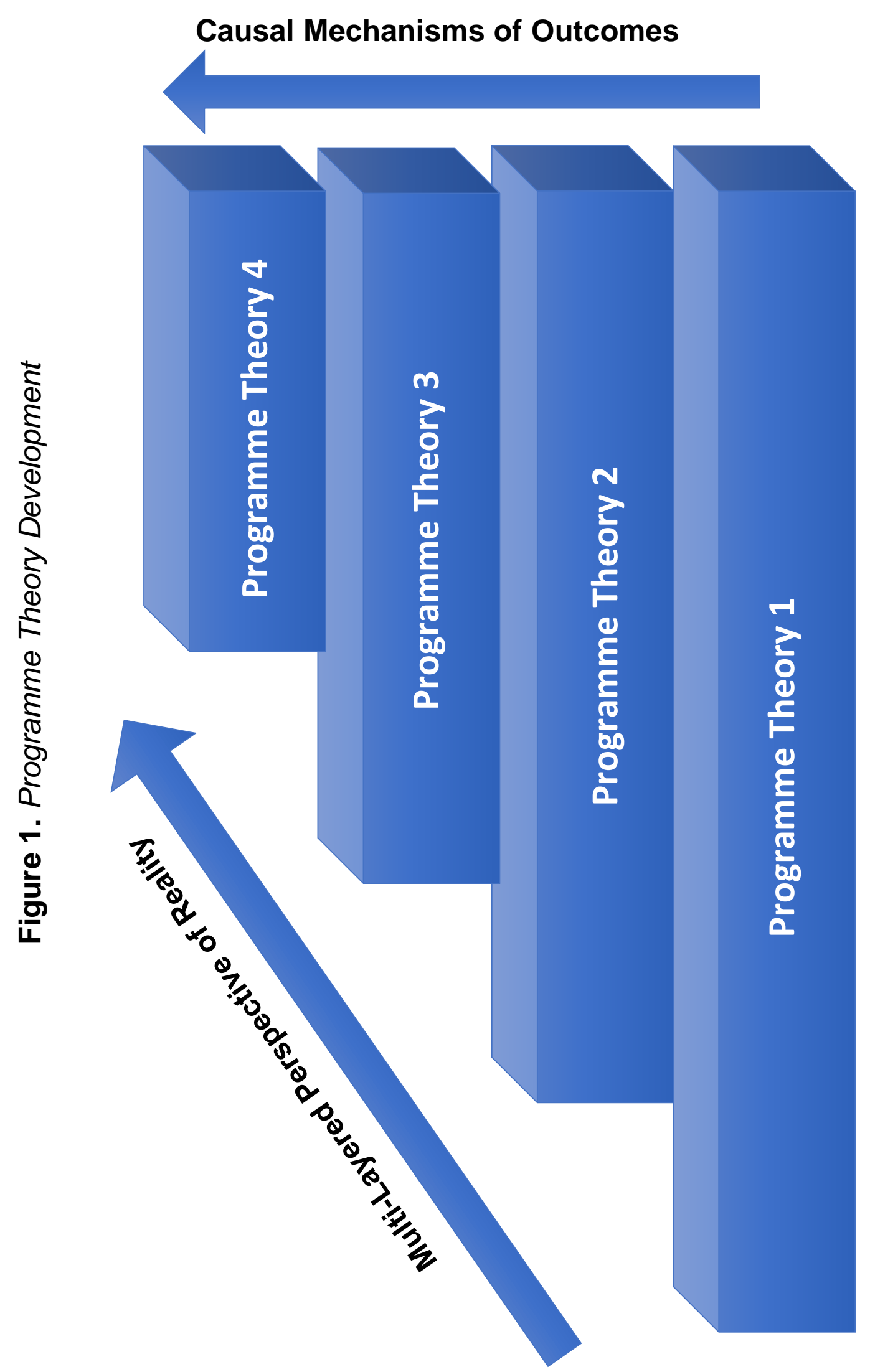

